\title{
INCIDENCE OF Enterococcus SPECIES IN RAW MILK AND SOME CHEESES
}

Tohamy, M. M. ; M. A. Nour ; A. A. Elhadidi ; K. A. A. Khater and Sh. A. Abdella

Dairy Dept., Fac. Agric., Al Azhar University, Cairo, Egypt.

\section{ABSTRACT}

The incidence of enterococci in Raw milk, Karish cheese, Ras cheese and Domiati cheese was investigated by using three different selective media. All isolated enterococci were identified on genus and species levels.

Higher, minimum, and maximum log counts were obtained by using KF medium being $10^{6}-10^{7}(\mathrm{~min})$ and $10^{8}(\max )$. These figures were $10^{3}-10^{5}(\mathrm{~min})$ and $10^{6}$ (max) by using BEA and CATC media. Accordingly, KF medium could be considered the best for detection of enterococci incidence.

The obtained results showed that the isolated Enterococcus from milk and cheeses studied were identified as E. faecalis $26(32.5 \%)$, E. faecium $25(31.25 \%)$ and E. durans 29 (36.25\%), respectively.

Most identified $E$. durans was observed in Karish cheese (15 out of 20), followed by Raw milk ( 9 out of 20) and only 3 and $5 E$. durans were isolated from Ras cheese and Domiati cheese. On the other hand, most isolated Enterococcus spp. from Ras cheese (14 out of 20) were E. faecalis. However, approximately half (9 and 8 out of 20) of identified Enterococcus spp. from Domiati cheese and Raw milk were E. faecium.

All isolated strains were identified by using the biochemical characteristics. The results showed that all tested isolates belonged to genus Enterococcus.

\section{INTRODUCTION}

The most controversial species of lactic acid bacteria found in food products are the enterococci. They are present as a component of the natural microflora of certain foods such as dairy products. Enterococci are normal inhabitants of gastrointestinal tracts of both human and animals (Bhardwaj et al, 2011) . E. faecium and E. faecalis are the two predominant species in human intestine (Giraffa. 2003).

Although enterococci are considered to be important in foods, some strains have detrimental activities that include spoilage of foods and dairy products. Both $E$. faecalis and $E$. faecium species are relatively heat resistant as well.

The perception of the presence of enterococci in milk is due to contact with cows feces has now changed due to the fact that it is very common to find enterococci in other sources as well contradicting what was formerly a sole fecal contamination belief. Giraffa. (2003) stated that enterococci can enter into the cheese milk either primarily from human or animal feces, but also secondarily from contaminated water sources, the exterior of the animal or other contaminated milking equipment or bulk storage tanks handled in the processing plant. The objective of this work was to study the incidence of Enterococcus spp. in raw milk and some cheeses by 
Tohamy, M. M. et al.

using different selective media, and to identify these isolates on genus and species levels.

\section{MATERIALS AND METHODS}

Milk and some dairy products samples (cheeses) were collected from Cairo and El Gammalia city markets at Dakahlia governorate in sterile glass containers or sterilized polyethylene bags. Samples were transferred to laboratory in ice box and analyzed at the same day.

Enterococci counts were determined by using different selective media, namely bile aesculin azide agar (BEA), citrate azide tween carbonate agar (CATC) and KF Streptococcus Agar (KF). Pouring plate method was used, and plates were incubated for 2-3 days at $30{ }^{\circ} \mathrm{C}$ under aerobic condition.

Typical colonies isolated from different sources on BEA agar were transferred to TSA agar slants, which were incubated for $24 \mathrm{hr}$ at $37^{\circ} \mathrm{C}$ under aerobic condition. A maximum of four typical colonies from each sample were retained for complementary tests. After four successive purification on the same medium, a stock culture of each isolated culture was maintained through biomonthly transfers on trypticase soya agar (TSA) and stored at $4^{\circ} \mathrm{C}$. All isolates were transferred before use from stock culture into trypticase soya broth (TSB) and incubated at $37 \stackrel{\circ}{\circ}$ for $24 \mathrm{hr}$ under aerobic condition. Subsequently, to insure an active culture, two transfers of each culture to new tubes of TSB were carried out, followed by incubation as described.

For the identification on the genus level, Isolated typical colonies were primary identified on genus level according to American Public Health Association (1992). Experiment was designed by using 18h culture grown in TSB broth at $37^{\circ} \mathrm{C}$. One $\mathrm{ml}$ of each $18 \mathrm{~h}$ culture was added to $9 \mathrm{ml}$ TSB broth and incubated at $10{ }^{\circ} \mathrm{C}, 45{ }^{\circ} \mathrm{C}$ and $60 \stackrel{\circ}{\circ} \mathrm{C}$ for $24 \mathrm{hr}, 24 \mathrm{hr}$ and $30 \mathrm{~min}$, respectively.

One $\mathrm{ml}$ of each $18 \mathrm{~h}$ culture was added to $9 \mathrm{ml}$ of TSB broth adjusted to $\mathrm{pH} 9.6$ by using sodium hydroxide, adjusted to Nacl $6.5 \%$ by using sodium chloride and adjusted to bile $40 \%$ by using bile salts and to sodium azide $0.04 \%$ by using sodium azide. Cultures were incubated at $37{ }^{\circ} \mathrm{C}$ under aerobic condition for $24 \mathrm{hr}$.

Regaring the Identification on the species level, peptone water medium was used for the carbohydrate fermentation for all purified Enterococci isolates. To $900 \mathrm{ml}$ peptone water, $10 \mathrm{ml}$ indicator solution were added (bromocrysol purple $0.2 \%$ ethyl alcohol). $10 \mathrm{~g}$ of the appropriate sugar were disolved in $90 \mathrm{ml}$ distilled water and steamed for $30 \mathrm{~min}$, and was added to sterile base. Peptone water medium was inoculated with Enterococci isolates, and then examined after 7 days for acid production. A positive reaction was recorded when the broth medium (purple color) turns yellow. The carbohydrate broth was inoculated with a drop or loopful of an overnight broth culture or by several colonies taken from nutrient agar plate's i.e, the inoculum was taken from a fresh culture. $\mathrm{D}(-)$ mannitol, L(-) sorbose, $\mathrm{L}(-)$ arginine , $\mathrm{D}(-)$ arabinose, $\mathrm{D}(-)$ sorbitol, $\mathrm{D}(-)$ raffinose, potassium tellurite, $\mathrm{D}(-)$ 
sucrose and sodium pyruvate were used for such purpose. This assay was performed according to (Tahoun. 2010).

\section{RESULTS AND DISCUSSION}

Incidence of Enteococci in studied Raw milk and some cheeses:

In this study, the incidences of enterococci in Raw milk, Karish cheese, Ras cheese and Domiati cheese samples was investigated. Besides, comparative study of different selective media was also performed. All isolated enterococci were identified on genus and species levels.

Enterococci counts in Domiati cheese samples on BEA agar medium were of similar minimum and maximum log counts, being $10^{4}$ and $10^{6}$, expect one sample $\left(\operatorname{Dc} 11^{3}\right)$. Table (3) show that the minimum and maximum log counts of enterococci grown on CATC medium were mostly similar and ranged from $10^{5}$ to $10^{6}$ expect five samples, being $R m 8, R m 10$, Rc4, Dc2 and Kc3, which were of maximum log count of $10^{7}$. Higher minimum and maximum log count was observed with KF medium , which were $10^{7}$ and $10^{8}$ in Raw milk and Ras cheese samples, expect one sample, being Rm2, $\left(1^{6}\right)$. In addition, enterococci counts on KF media also showed high, minimum and maximum log counts being $10^{6}$ and $10^{7}$ in all Domiati cheese and Karish cheese samples expect Dc2 and Kc3 samples $\left(10^{8}\right)$. It seems to be true that imputably similar contamination level with enterococci in raw milk and different cheeses was observed.

KF medium could be considered as the best medium for enterococci count in the studied milk and cheeses. KF medium showed higher minimum and maximum count (Tables 1 and 2) for all tested Raw milk (10) and cheese samples (30) being $7 \times 10^{6}-3.9 \times 10^{8}$ ( Raw milk samples), $1.3 \times 10^{7}$ $2.3 \times 10^{8}$ (Ras cheese samples), $1.5 \times 10^{6}-1.4 \times 10^{8}$ (Domiati cheese samples) and $3.7 \times 10^{7}-1 \times 10^{8}$ (Karish cheese samples). Followed by CATC medium, being $3.7 \times 10^{5}-1.1 \times 10^{7}$ (Raw milk samples), $1.5 \times 10^{5}-1.5 \times 10^{7}$ (Ras cheese samples), $1.4 \times 10^{5}-2.8 \times 10^{7}$ (Domiati cheese samples) and $3.6 \times 10^{6}-1.3 \times 10^{7}$ (Karish cheese samples), respectively.

Table (1): Enterococci count in studied Raw milk and Ras cheese samples by using different selective media.

\begin{tabular}{|c|c|c|c|c|c|c|c|}
\hline \multirow{2}{*}{ Samples } & \multicolumn{3}{|c|}{ Selective media } & \multirow{2}{*}{ Samples } & \multicolumn{3}{|c|}{ Selective media } \\
\hline & -BEA & CATC & $\mathbf{E F}$ & & $\bullet$ BEA & CATC & घKF \\
\hline${ }^{*} \mathrm{Rm} 1$ & $6.5 \times 10^{5}$ & $2.9 \times 10^{6}$ & $2.9 \times 10^{7}$ & ${ }^{\star} \mathrm{Rc} 1$ & $6.2 \times 10^{4}$ & $1.5 \times 10^{5}$ & $1.3 \times 10^{7}$ \\
\hline $\mathrm{Rm} 2$ & $1 \times 10^{6}$ & $1.9 \times 10^{6}$ & $2 \times 10^{6}$ & Rc2 & $1.3 \times 10^{5}$ & $1.7 \times 10^{5}$ & $1.3 \times 10^{8}$ \\
\hline $\mathrm{Rm} 3$ & $1 \times 10^{4}$ & $3.7 \times 10^{5}$ & $7 \times 10^{7}$ & Rc3 & $7.8 \times 10^{5}$ & $4.8 \times 10^{6}$ & $2.03 \times 10^{7}$ \\
\hline $\mathrm{Rm} 4$ & $1.2 \times 10^{5}$ & $1.3 \times 10^{6}$ & $1.5 \times 10^{7}$ & Rc4 & $1.9 \times 10^{6}$ & $1.5 \times 10^{7}$ & $2.3 \times 10^{8}$ \\
\hline $\mathrm{Rm} 5$ & $1.1 \times 10^{6}$ & $1.6 \times 10^{6}$ & $4.3 \times 10^{7}$ & Rc5 & $5.9 \times 10^{5}$ & $3.08 \times 10^{6}$ & $5 \times 10^{7}$ \\
\hline $\mathrm{Rm} 6$ & $1.3 \times 10^{6}$ & $2.2 \times 10^{6}$ & $9 \times 10^{7}$ & Rc6 & $3.8 \times 10^{5}$ & $1.29 \times 10^{6}$ & $1.36 \times 10^{7}$ \\
\hline $\mathrm{Rm} 7$ & $4.5 \times 10^{5}$ & $1.2 \times 10^{6}$ & $4.5 \times 10^{7}$ & Rc7 & $1.33 \times 10^{6}$ & $3.8 \times 10^{6}$ & $3.54 \times 10^{7}$ \\
\hline $\mathrm{Rm} 8$ & $9.6 \times 10^{5}$ & $1 \times 10^{7}$ & $3.9 \times 10^{8}$ & Rc8 & $2.06 \times 10^{6}$ & $3.26 \times 10^{6}$ & $2.5 \times 10^{7}$ \\
\hline $\mathrm{Rm} 9$ & $2.3 \times 10^{5}$ & $3.5 \times 10^{6}$ & $1.6 \times 10^{7}$ & Rc9 & $1.13 \times 10^{6}$ & $1.42 \times 10^{6}$ & $1.7 \times 10^{7}$ \\
\hline $\mathrm{Rm} 10$ & $8.2 \times 10^{5}$ & $1.1 \times 10^{7}$ & $2.7 \times 10^{8}$ & Rc10 & $1.5 \times 10^{6}$ & $4.22 \times 10^{6}$ & $3.44 \times 10^{7}$ \\
\hline
\end{tabular}

"Rm= Raw Milk *Rc= Ras cheese $\bullet B E A=$ Bile Aesculin Azide Agar

$\checkmark \mathrm{CATC}=$ Citrate Azide Tween Carbonate Agar $\quad \mathrm{KF}=$ Streptococcus Agar 
Table (2): Enterococci count in studied Domiati cheese and Karish cheese samples by using different selective media.

\begin{tabular}{|c|c|c|c|c|c|c|c|}
\hline \multirow{2}{*}{ Samples } & \multicolumn{3}{|c|}{ Selective media } & \multirow{2}{*}{ Samples } & \multicolumn{3}{|c|}{ Selective media } \\
\hline & -BEA & $\checkmark$ CATC & EKF & & -BEA & $\checkmark$ CATC & EKF \\
\hline${ }^{\star} \mathrm{Dc} 1$ & $3 \times 10^{3}$ & $1.4 \times 10^{5}$ & $1.5 \times 10^{6}$ & ${ }^{\star} \mathrm{Kc1}$ & $3.4 \times 10^{5}$ & $7 \times 10^{6}$ & $4.9 \times 10^{7}$ \\
\hline Dc2 & $2.9 \times 10^{6}$ & $2.8 \times 10^{7}$ & $1.4 \times 10^{8}$ & $\mathrm{Kc2}$ & $6.4 \times 10^{5}$ & $9.4 \times 10^{6}$ & $8.6 \times 10^{7}$ \\
\hline Dc3 & $1.4 \times 10^{4}$ & $2.8 \times 10^{5}$ & $2.7 \times 10^{6}$ & Kc3 & $3.8 \times 10^{6}$ & $1.3 \times 10^{7}$ & $1 \times 10^{8}$ \\
\hline Dc4 & $8 \times 10^{4}$ & $4.4 \times 10^{5}$ & $1.9 \times 10^{7}$ & Kc4 & $5.4 \times 10^{5}$ & $5.3 \times 10^{6}$ & $3.7 \times 10^{7}$ \\
\hline Dc5 & $8.9 \times 10^{4}$ & $4.2 \times 10^{5}$ & $9.8 \times 10^{6}$ & Kc5 & $2 \times 10^{5}$ & $3.6 \times 10^{6}$ & $4.3 \times 10^{7}$ \\
\hline Dc6 & $4.3 \times 10^{5}$ & $8.13 \times 10^{5}$ & $4.2 \times 10^{7}$ & Kc6 & $9.8 \times 10^{5}$ & $7.3 \times 10^{6}$ & $6.7 \times 10^{7}$ \\
\hline Dc7 & $1.8 \times 10^{5}$ & $6.6 \times 10^{5}$ & $2.3 \times 10^{7}$ & $\mathrm{Kc7}$ & $6 \times 10^{5}$ & $4.3 \times 10^{6}$ & $6 \times 10^{7}$ \\
\hline Dc8 & $3.9 \times 10^{5}$ & $2.1 \times 10^{6}$ & $7.3 \times 10^{7}$ & Kc8 & $3.6 \times 10^{5}$ & $6.1 \times 10^{6}$ & $4.6 \times 10^{7}$ \\
\hline Dc9 & $6.2 \times 10^{5}$ & $1.8 \times 10^{6}$ & $3.9 \times 10^{7}$ & Kc9 & $1.8 \times 10^{6}$ & $8.6 \times 10^{6}$ & $7.8 \times 10^{7}$ \\
\hline Dc10 & $3.4 \times 10^{5}$ & $1.8 \times 10^{6}$ & $3.7 \times 10^{7}$ & Kc10 & $3 \times 10^{6}$ & $9.2 \times 10^{6}$ & $7.5 \times 10^{7}$ \\
\hline
\end{tabular}

${ }^{\star}$ Dc = Domiati cheese *Kc = Karish cheese •BEA= Bile Aesculin Azide Agar

-CATC= Citrate Azide Tween Carbonate Agar aKF Streptococcus Agar

Table (3): Minimum and maximum counts of Enterococci in studied dairy samples by using different selective media.

\begin{tabular}{|c|c|c|c|c|c|c|}
\hline \multirow{2}{*}{ Samples } & \multicolumn{2}{|c|}{-BEA } & \multicolumn{2}{|c|}{ CATC } & \multicolumn{2}{|c|}{-KF } \\
\hline & Min. & Max. & Min. & Max. & Min. & Max. \\
\hline $\begin{array}{l}\text { Raw milk } \\
\text { Ras cheese }\end{array}$ & $\begin{array}{c}1 \times 10^{4} \\
6.2 \times 10^{4}\end{array}$ & $\begin{array}{c}1.3 \times 10^{6} \\
2.06 \times 10^{6}\end{array}$ & $\begin{array}{l}3.7 \times 10^{5} \\
1.5 \times 10^{5}\end{array}$ & $\begin{array}{l}1.1 \times 10^{7} \\
1.5 \times 10^{7}\end{array}$ & $\begin{array}{c}7 \times 10^{6} \\
1.3 \times 10^{7}\end{array}$ & $\begin{array}{l}3.9 \times 10^{8} \\
2.3 \times 10^{8}\end{array}$ \\
\hline $\begin{array}{l}\text { Domiati } \\
\text { cheese }\end{array}$ & $3 \times 10^{3}$ & $2.9 \times 10^{6}$ & $1.4 \times 10^{5}$ & $2.8 \times 10^{7}$ & $1.5 \times 10^{6}$ & $1.4 \times 10^{8}$ \\
\hline $\begin{array}{l}\text { Karish } \\
\text { cheese }\end{array}$ & $2 \times 10^{5}$ & $3.8 \times 10^{6}$ & $3.6 \times 10^{6}$ & $1.3 \times 10^{7}$ & $3.7 \times 10^{7}$ & $1 \times 10^{8}$ \\
\hline
\end{tabular}

-BEA= Bile Aesculin Azide Agar

-CATC= Citrate Azide Tween Carbonate Agar

Finally the lowest enterococci count was observed by using BEA being $1 \times 10^{4}-1.3 \times 10^{6}$ (Raw milk), $6.2 \times 10^{4}-2.06 \times 10^{6}$ (Ras cheese), $3 \times 10^{3}$ $2.9 \times 10^{6}$ (Domiati cheese) and $2 \times 10^{5}-3.8 \times 10^{6}$ (Karish cheese).

Approximately similar contamination levels were observed in literature. Enterococci are associated with traditional European cheeses manufactured in Mediterranean countries from raw or pasteurized goats, ewes, water - buffaloes or bovine milk (Xanthopoulos et al. 2000, Sarantinopoulos et al. 2002 and Manolopoulou et al. 2003). Levels of enterococci in different cheese curds ranged from $10^{4}$ to $10^{6} \mathrm{cfu} / \mathrm{g}$, and in fully ripened cheese from $10^{5}$ to $10^{7} \mathrm{cfu} / \mathrm{g}$ (Sarantinopoulos et al. 2001, Franz et al. 2003, and Giraffa. 2002 and Manolopoulou et al. 2003). Similarly, the number of enterococci in different cheeses ranged from 4 to $6 \mathrm{cfu} / \mathrm{g}$ and from 4 to $7 \mathrm{cfu} / \mathrm{g}$ in full - matured cheese (Saaverdra et al, 2003). In certain cheeses enterococci can reach counts of up to $10^{6}-10^{8} \mathrm{cfu} / \mathrm{g}$ and may play an important role in the organoleptic characteristics during ripening (Psoni et al, 2003). Giraffa. (2003) approved E. faecium K77D as a starter culture for ripening of cheese in Denmark.

On the other hand, high contamination levels in raw milk samples tested were observed comparing with that observed by Hill and Smyth. (1997), who found that minimum and maximum levels of enterococci in raw cows milk were $<10^{1} \mathrm{cfu} / \mathrm{g}$ and $1.2 \times 10^{3}$. Other sources reported numbers in 
European raw milk varying from $10^{3}$ cells $/ \mathrm{ml}$ to $10^{5} \mathrm{cells} / \mathrm{ml}$ or more (Perez et al. 1982, Suzzi et al. 2000, Cogan et al. 1997 and Del Pozo et al. 1988).

The average, maximum and minimum counts of enterococci in Egyptian Ras cheese were $4.4 \times 10^{5} \mathrm{cfu} / \mathrm{g}, 8 \times 10^{6} \mathrm{cfu} / \mathrm{g}$ and $7.7 \times 10^{2} \mathrm{cfu} / \mathrm{g}$ respectively, (Sharaf et al. 1997). This figures were obtained by using thallous acetate tetrazolium glucose agar according to Barnes. (1956). In addition, Bahout et al. (2006) found that the average, maximum and minimum counts of enterococci in Karish cheese were $5.7 \times 10^{6} \mathrm{cfu} / \mathrm{g}, 3.5 \times 10^{7} \mathrm{cfu} / \mathrm{g}$ and $9.2 \times 10^{3} \mathrm{cfu} / \mathrm{g}$, respectively. It showed be stated here that there is no any available informations concerning the were of the will known selective Enterococci media such as KF, BEA and CATC for studying the incidence of Egyptian dairy products or milk.

For identification of isolated bacteria on the genus level, grown on the Enterococci selective medium BEA, the classical phenotype - based (biotyping) method was followed. Domig et al. (2003) stated that in spite of the advantage of genotype methods, the biotyping methods are still important for dairy routine analysis. Jurkovic et al. (2006) identified Enterococci on the genus level by several conventional phenotypic methods similar to phenotypic method used in this study.

All isolated cultures (80) grown on BEA agar media were identified on the genus level by several conventional methods: Gram stain, Catalase production, growth at $10^{\circ} \mathrm{C}$ and $45^{\circ} \mathrm{C}$ and in $6.5 \% \mathrm{Nacl}, \mathrm{pH} 9.6$ in combination with resistance to bile $40 \%$, sodium azide $0.04 \%$ and $60^{\circ} \mathrm{C} / 30$ min. All tested cultures grown on Enterococcus selective medium BEA (untabulated results) showed similar behavior that all were able to grow at $10^{\circ} \mathrm{C}$ and $45^{\circ} \mathrm{C}, \mathrm{pH} 9.6$, Nacl $6.5 \%$ and resist $40 \%$ bile and $0.04 \%$ sodium azide, besides, survive $60^{\circ} \mathrm{C} / 30 \mathrm{~min}$.

Identification of isolated Enterococcus strains on the species level, was done by the identification program, according to (Tahoun. 2010).

In general all tested Enterococcus spp were belonged to E. faecalis, E. faecium and E. durans, being 26 (32.5\%), 25 (31.25\%) and 29 (36.25\%), respectively. The study done by El - Shafei et al. (2002) showed that two hundred strains of Lactic acid bacteria were isolated from traditional Egyptian fermented milk (Laben Rayeb) and identified according to their morphological and physiological characteristics. They found that $80(40 \%)$ strains were identified as Enterococcus, and then carbohydrate fermentation were carried on 80 Enterococcus species and were identified as E. faecium (60) and E. faecalis (20). In addition, Dabiza et al. (2005) isolated two hundred strains of Lactic acid bacteria from samples of raw buffaloes and cows milk, traditional fermented milk (Laban Rayeb), and Karish, Ras and Cheddar cheeses collected from the local market. The strains were identified by using of API 20 and API $50 \mathrm{CH}$ Strips and API CHL medium and the results showed that 46 strains were identified as $E$. faecium and 13 strains were identified as $E$. faecalis.

Ayad et al. (2006) isolated 1340 strains of lactic acid bacteria from Ras cheese during manufacture and ripening, and were identified by biochemical and physiological characteristics, 715 strains were identified as Enterococcus spp and these isolates were characterized to species by using 
API system and identification of some strains was confirmed by using SDS PAGE Technique. Results showed that 480 strains were identified as faecium, (63) E. faecalis, (120) E. durans and (52) E. spp.

Results of (Table 5) also show that most $E$. faecalis was isolated from Ras cheese samples followed by Domiati cheese, being 14, 6 and 3from each of Raw milk and Karish cheese. While E. faecium was mostly isolated from Domiati cheese samples (9) followed by Raw milk, Karish cheese and Ras cheese samples being 8,5 and 3 isolates, respectively.

Finally, most $E$. durans were isolated from Karish cheese and Raw milk samples, being 21 out of the 29 isolates. These results are in agreement except with Karish cheese with that reported by Franz et al. (1999), Giraffa. (2003) and Sarantinopoulos et al. (2001). They stated that among enterococci, E. faecium, E. faecalis and to lesser extent $E$. durans are generally the most frequent and prevalent species in cheeses. As mentioned above, numbers of $E$. durans isolates were 3,5 and 12 among the 20 Enterococcus spp of each cheese. In agreement with our results Ali. (2011) stated that $E$. faecalis, E. faecium and E. durans were only Enterococcus spp isolated from raw milk.

Table (4): Identification of isolated enterococci on species level.

\begin{tabular}{|c|c|c|c|c|c|c|c|c|c|c|}
\hline \multirow[b]{2}{*}{ No. of isolates } & \multicolumn{9}{|c|}{ Phenotypic characteristics } & \multirow[b]{2}{*}{ Species } \\
\hline & 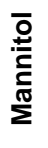 & 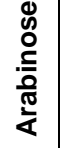 & 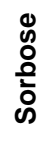 & 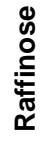 & 竞 & હ & $\begin{array}{l}\overline{0} \\
\stackrel{2}{0} \\
\text { 훙 }\end{array}$ & 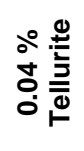 & 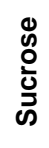 & \\
\hline $\begin{array}{l}{ }^{*} \mathrm{Rm} 1-1, \mathrm{Rm} 1-2, \mathrm{Rm} 2-2, \\
\text { Rm3-1, Rm3-2, Rm7-2, } \\
\text { Rm8-1, Rm8-2, Rm9-1 }\end{array}$ & - & - & - & - & + & + & - & - & - & \multirow{4}{*}{ E.durans } \\
\hline Rc3-2, Rc4-1, Rc5-1* & - & - & - & - & + & + & - & - & - & \\
\hline $\begin{array}{l}\text { Dc6-1, Dc6-2, Dc9-1, * } \\
\text { Dc9-2, Dc10-1 }\end{array}$ & - & - & - & - & + & + & - & - & - & \\
\hline $\begin{array}{l}\mathrm{K} 1-1, \mathrm{~K} 2-2, \mathrm{~K} 4-1, \mathrm{~K} 4-2,{ }^{*} \\
\mathrm{~K} 5-1, \mathrm{~K} 5-2, \mathrm{~K} 6-1, \mathrm{~K} 7-2, \\
\mathrm{~K} 8-1, \mathrm{~K} 9-1, \mathrm{~K} 9-2, \mathrm{~K} 10-1\end{array}$ & - & - & - & - & + & + & - & - & - & \\
\hline $\begin{array}{l}\text { Rm2-1, Rm4-1, Rm4-2, } \\
\text { Rm5-1, Rm5-2, Rm6-1, } \\
\text { Rm6-2, Rm7-1 }\end{array}$ & + & + & - & - & + & + & - & - & + & \multirow{4}{*}{ E.faecium } \\
\hline Rc2-1, Rc3-1, Rc7-1 & + & + & - & - & + & + & - & - & + & \\
\hline $\begin{array}{l}\text { Dc1-1, Dc4-1, Dc4-2, } \\
\text { Dc5-1, Dc7-1, Dc7-2, } \\
\text { Dc8-1, Dc10-2 }\end{array}$ & + & + & - & - & + & + & - & - & + & \\
\hline $\begin{array}{l}\mathrm{K} 1-2, \mathrm{~K} 3-1, \mathrm{~K} 3-2, \\
\mathrm{~K} 6-2, \mathrm{~K} 8-2\end{array}$ & + & + & - & - & + & + & - & - & + & \\
\hline Rm9-2, Rm10-1, Rm10-2 & + & - & - & - & + & + & + & + & + & \multirow{4}{*}{ E.faecalis } \\
\hline $\begin{array}{l}\text { Rc1-1, Rc1-2, Rc2-2, } \\
\text { Rc4-2, Rc5-2, Rc6-1, } \\
\text { Rc6-2, Rc7-2, Rc8-1, } \\
\text { Rc8-2, Rc9-1, Rc9-2, } \\
\text { Rc10-1, Rc10-2 }\end{array}$ & + & - & - & - & + & + & + & + & + & \\
\hline $\begin{array}{l}\text { Dc1-2, Dc2-1, Dc2-2, } \\
\text { Dc3-1, Dc3-2, Dc5-2 }\end{array}$ & + & - & - & - & + & + & + & + & + & \\
\hline K2-1, K7-1, K10-2 & + & - & - & - & + & + & + & + & + & \\
\hline
\end{tabular}


Table (5): Number and percentage of identified Enterococcus spp.

\begin{tabular}{|c|c|c|c|c|c|c|c|c|c|c|}
\hline \multirow{3}{*}{ Species } & \multicolumn{8}{|c|}{ No. of isolates } & \multirow{2}{*}{\multicolumn{2}{|c|}{ Total }} \\
\hline & \multicolumn{2}{|c|}{ Raw milk } & \multicolumn{2}{|c|}{ Ras cheese } & \multicolumn{2}{|c|}{$\begin{array}{l}\text { Domiati } \\
\text { cheese }\end{array}$} & \multicolumn{2}{|c|}{ Karish cheese } & & \\
\hline & No & $\%$ & No & $\%$ & No & $\%$ & No & $\%$ & No & $\%$ \\
\hline E.faecalis & 3 & 3.75 & 14 & 17.5 & 6 & 7.5 & 3 & 3.75 & 26 & 32.5 \\
\hline E.faecium & 8 & 10 & 3 & 3.75 & 9 & 11.25 & 5 & 6.25 & 25 & 31.25 \\
\hline E.durans & 9 & 11.25 & 3 & 3.75 & 5 & 6.25 & 12 & 15 & 29 & 36.25 \\
\hline
\end{tabular}

\section{REFERENCES}

Ali, A. A. (2011). Isolation and identification of lactic acid bacteria from raw cow milk in khartoum state, Sudan. International Journal of Dairy Science, 6 (1): $66-71$.

American Public Health Association (1992). Compendium of methods for the microbiological examination of foods. 3TH. ED. (APHA). Washington, DC.

Ayad, E. H. E., Abdallah, H. M., Darwish, S. M., and El - Soda, M. (2006). Identification of lactic acid bacteria of Artisanal Egyptian Ras Cheese. Egyptian J. Dairy Sci ISSN 0378 - 270 Vol. 34 pp. $139-144$.

Bahout, A. A., and Moustafa, A. H. (2006). Occurrence of some microorganisms in relation to public health in karish cheese. Assiut Vet. Med. J. Vol. 52 (111), October, pp $85-92$.

Barnes, E. M. (1956). Method for the isolation of faecal streptococci (Lancefield Group D) from bacon factones. J. Appl. Bact. 19, 193.

Bhardwaj Arun, Kaur Gurpreet, Gupta Hitta, Vij Shilpa and Malik Ravinder K. (2011). Interspecies diversity, safety and probiotic potential of bacteriocinogenic Enterococcus faecium isolated from dairy food and human faeces. World J Microbiology Biotechnology, 27: 591 - 602, doi: 10. 1007.

Cogan, T. M., Barbosa, M., Beuvier, E., BianchiSalvadori, B., Cocconcelli, P. S., Fernandes, I., Gomez, J., Gomez, R., Kalantzopoulos, G., Ledda, A., Medina, M., Rea, M. C., and Rodriquez, E. (1997). Characterization of the lactic acid bacteria in artisanal dairy products. Journal of Dairy Research, 64(3): $409-421$.

Dabiza, N. M. A., Effat, B. A., and Sharaf, O.M. (2005). The antibacterial effect of probiotic bacteria isolated from some dairy products. Egyptian J. Dairy Sci ISSN 0378 - 2700 Vol. 33 pp. $49-64$.

Del Pozo, B. F., Gaya, P., Medina, M., Rodriguez - Marin, M. A., and Nunez, M. (1988). Changes of microflora of La Serena ewes milk cheese during ripening. Journal of Dairy Research 55, $449-455$.

Domig, Konrad. J., Mayer, Helmut. K., and Kneifel, Wolfgang. (2003). Methods used for the isolation, enumeration, characterization and identification of Enterococcus spp. 1. Media for isolation and enumeration. International Journal of Food Microbiology 88, 147 - 164.

El - Shafei, K., Ibrahim, G. A. and Tawfik, N. F. (2002). Beneficial uses of locally isolated lactic acid bacteria. Egyptian J. Dairy Sci ISSN $0378-$ 2700 Vol. 30 pp. $15-25$. 
Franz, C. M. A. P., Holzapfel, W. H., and Stiles, M. E. (1999). Enterococci at the crossroads of food safety? International Journal of Food Microbiology 47, $1-24$

Franz, Charles M.A.P., Stiles, M., Schleifer, K., and Holzapfel, W. H. (2003). Enterococci in foods - a conundrum for food safety. International Journal of Food Microbiology 88, $105-122$.

Giraffa, G. (2002). Enterococci from foods. FEMS Microbiology, 26, 163 171.

Giraffa, G. (2003). Functionality of enterococci in dairy products. International Journal of Food Microbiology 88, $215-222$.

Hill, B. M., and Smythe, B. W. (1997). A study of the microbiological quality of raw milk from individual farms. New Zealand Dairy Research Institute, 1- 35.

Jurkovic, D., Krizkova, L., Dusinsky, R., Belicova, A., Sojka, M., Krajcovic, J., and Ebringer, L. (2006). Identification and characterization of enterococci from bryndza cheese. Applied Microbiology ISSN 0266 8254 Vol. 42 pp. $553-559$.

Manolopoulou, E., Sarantinopoulos, P., Zoidou, E., Aktypis, A., Moschopoulou, E., Kandarakis, I. G., and Anifantakis, E. M. (2003). Evolution of microbial populations during traditional feta cheese manufacture and ripening. International Journal of Food Microbiology $82,153-161$.

Perez, B. S., Lorenzo, P. L., Garcia, M. L., Hernandez, P. E., and Ordonez, J. A. (1982). Heat - resistance of enterococci. Milchwissenschaft - Milk Science International, 37(12): $724-726$.

Psoni, L., Tzanetakis, N., and Litopoulou - Tzanetaki, E. (2003). Microbiological characteristics of Batzos, a traditional Greek cheese from raw goats milk. Food Microbiology 20, $575-582$.

Saavedra, Lucila., Taranto, Maria, Pia., Sesma, Fernando., and Valdez, Graciela. Font de. (2003). Homemade traditional cheeses for the isolation of probiotic Enterococcus faecium strains. International Journal of Food Microbiology 88, $241-245$.

Sarantinopoulos, P., Andrighetto, C., Georgalaki, M. D., Rea, M. C., Lombardi, A., Cogan, T. M., Kalantzopoulos, G., and Tsakalidou, E. (2001). Biochemical properties of enterococci relevant to their technological performance. International Dairy Journal 11, 621 - 647.

Sarantinopoulos, P., Kalantzopoulos, G., and Tsakalidou, E. (2002). Effect of Enterococcus faecium on microbiological, physicochemical and sensory characteristics of Greek feta cheese. International Journal of Food Microbiology 76, $93-105$.

Sharaf, O. M., Abd - Alla, Elsayed. A. M., and El - Shafei, Kawther. (1997). Clostridia, Enterobacteriaceae, Enterococci and its relation to biogenic amines content in Egyptian marketed Ras cheese. Egypt. J. Microbial Vol. 32 (1), $129-140$.

Suzzi, G., Caruso, M., Gardini, F., Lombardi, A., Vamini, L., Guerzoni, M. E., Andrighetto, C., and Lanorte, M. T. (2000). A survey of the enterococci isolated from an artisanal Italian goats cheese (semicotto caprino). Journal of Applied Microbiology 89, 267 - 274. 
Tahoun, U. M. A. (2010). Microbiological evaluation of reservoirs drinking water in Hurghada city. Requirements of the Master Degree of Science in Microbiology, Al-Azhar University.

Xanthopoulos, V., Polychroniadou, A., Litopoulou-Tzanetaki, E., and Tzanetakis, N. (2000). Characteristics of Anevato cheese made from raw or heat-treated goat milk inoculated with a lactic starter. Lebensmittel-Wissenschaft und-Technologie 33, $483-488$.

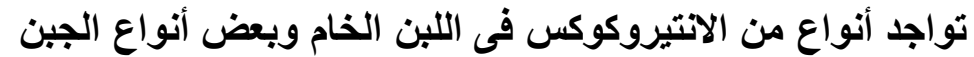

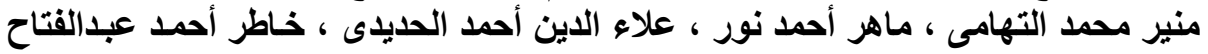

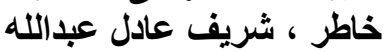
قسم الالبان - كلية الزراعة جامعة الازهر

تم دراسـة ـ ا ع عبنات من كلا من اللبن الخـام و الجبن الر اس و الجبن الدمياطى و الجبن

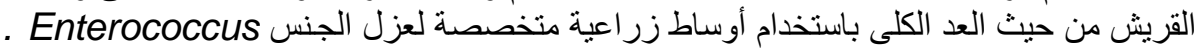

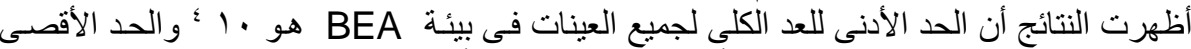

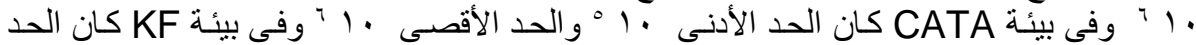

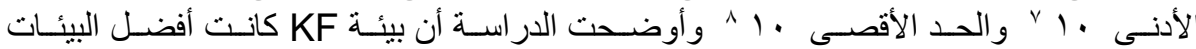

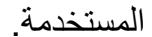

من ناحية أخرى تم تعريف السلالات المعزولة على البيئات السابقة باستخدام الخصائص

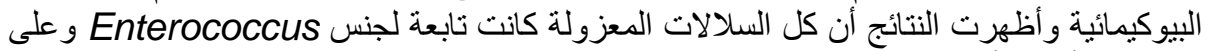

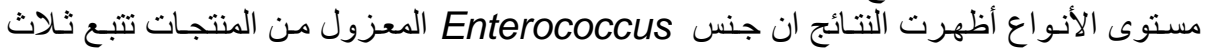
أنواع هى E. faecium و E. faecalis

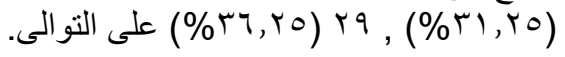

كلية الزراعة - جامعة المنصورة

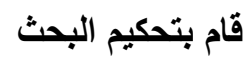

كلية الزراعة - جامعة الازهر

أ. أد / طه عبد الحبد الحليم نصيب

أ.د / أدمد فؤاد العريان 